\title{
NBSIR 73.255 \\ System for Preparation of Known Concentrations of Methane in Air
}

Ernest E. Hughes, William D. Dorko, and John K. Taylor

National Bureau of Standards

Department of Commerce

Washington, D. C. 20234

October 1973

Final Report

Prepared for

National Institute for Occupational Safety and Health Division of Laboratories and Criteria Development

Cincinnati, Ohio 45202 



\section{SYSTEM FOR PREPARATION OF KNOWN CONCENTRATIONS OF METHANE IN AIR}

Ernest E. Hughes, William D. Dorko, and John K. Taylor

National Bureau of Standards

Department of Commerce

Washington, D. C. 20234

October 1973

Final Report

Prepared for

National Institute for Occupational Safety and Health

Division of Laboratories and Criteria Development

Cincinnati, Ohio 45202

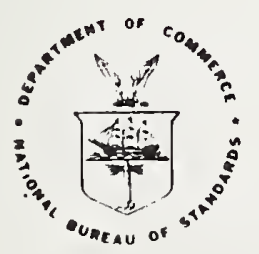

U. S. DEPARTMENT OF COMMERCE, Frederick B. Dent, Secretary

NATIONAL BUREAU OF STANDARDS, Richard W. Roberts, Director 



\section{TABLE OF CONTENTS}

$\underline{\text { Page }}$

1. Introduction 1

2. Description of System 1

3. Operation of System 2

4. Chromatographic Analysis of Methane Mixtures 4

5. Response Time - Generating System 5

6. Response Time - External Exposure Chamber 5

7. Operation - Summary of Instructions 6

8. Safety Precautions 7

9. Parts and Maintenance 7 
1. Schematic Diagram of Methane Generating System

2. Photograph of the Front of Methane System Including Separate Chamber

3. Photograph of the Rear and Interior of Methane System

4. Typical Calibration Curve

5. Calibration of FM-1 Air Flow Rotameter tube: $R-2-15 C$

6. Calibration of FM-2 Methane Flow Rotameter tube: $\mathrm{R}-2-15 \mathrm{AA}$

7. Plot of Reciprocal of Air Flow Versus Concentration of Methane Produced at a Fixed Flow of Methane

8. Schematic Diagram of Gas Chromatograph Sampling and Analysis System

9. Response of Generating System to Changes in Methane Concentration

10. Response Time of External Exposure Chamber

11. Sketch of Mixing Chamber and Sampling Manifold

\section{LIST OF TABLES}

1. Typical Calibration Data

2. Data Obtained at Constant Flow of Methane and Various Flows of Air

3. Air Flow Necessary to Produce Specific Concen-

4. Reproducibility of the System When Used to Produce Specific Concentrations of Methane

5. Response Time of Generating System

6. Response Time of External Chamber 
SYSTEM FOR PREPARATION OF KNOWN CONCENTRATIONS

OF METHANE IN AIR

\section{ABSTRACT}

A gas generating system is described for

producing concentrations of methane between 0.5 and 5.0 mole percent in air or other gases. The system has been evaluated and a calibration procedure is described. The system is equipped with adequate safety measures so that mixtures in the explosive range can be generated safely.

\section{INTRODUCTION}

This system produces mixtures of methane in air at concentrations ranging from fractions of a percent to above 5 percent. Pure methane is metered into a mixing chamber where it is mixed with a metered stream of air. The combined stream then flows into a manifold where samples can be removed for calibration of instruments or for analysis. The system is provided with flashback arresters to prevent propagation of ignition within the system and check valves to prevent diffusion of methane into the air system or of air into the methane system. A connection is available for direct attachment to an instrument to be evaluated or to an instrument for analysis of the concentration of methane produced. In addition, a chamber is provided in which methane detectors which depend on diffusion of methane into the detector can be mounted for evaluation.

\section{DESCRIPTION OF SYSTEM}

The system is shown schematically in Figure 1 and a photograph of the system and the separate chamber are shown in Figure 2. Air at a pressure above 15 psi and below 150 psi is attached at the bulkhead connector marked "Air-In". . located at the rear of the chassis, Figure 3. Methane at a similar range of pressure as the air is connected to the system at the bulkhead connector marked "Methane-In" located next to the air connection. Flow of air and methane into the system are controlled with on-off valves marked "Air-On" and "Methane-On", respectively. These valves are identified as $\mathrm{V}-1$ and $\mathrm{V}-2$ in Figure 1 . The separate gases pass through differential flow controllers, DFC-1 and DFC-2, which control the air and methane, respectively. The flow of each gas is controlled by valves marked "Air-Flow" and "Methane-Flow", $\mathrm{V}-3$ and $\mathrm{V}-4$, respectively. The rate of flow of the air is 
indicated by FM-1 and the flow of methane is indicated by FM-2. Each gas then passes through a sintered metal filter which serves as a flashback arrester, F-1 and F-2, and then through a check valve, CV-1 or CV-2. The separate streams then pass into a mixing chamber and the resulting mixture passes to the sampling manifold. The sampling manifold has an opening through the front panel into which a probe may be inserted. This connection is threaded and may be capped. An additional connection located at the lower end of the manifold inside the case is attached to a bulkhead connector on the rear of the chassis marked "Sample Out". When the front port of the manifold is capped, the mixture exits from the manifold through the connection at the rear. The auxiliary chamber or an analytical instrument may be attached at this connector.

The entire system is constructed of metal with the exception of the glass rotameters. The valves, filters, flow controllers, and connectors are commercial items and can be readily obtained and replaced. All tubing is 1/4" O.D. by $0.032 "$ wall, refrigeration grade copper tubing. The mixing chamber and manifold are fabricated from standard size copper pipe fittings and large diameter copper pipe.

\section{OPERATION OF SYSTEM}

The concentration of methane produced by measured flows of air and methane can be calculated for concentrations up to about 2 percent. Above this concentration the observed value tends to decrease relative to the calculated value and the deviation becomes larger as the concentration increases (Figure 4). For this reason it is advisable to calibrate the system periodically to determine the exact relationship between observed flow rates and the concentration produced. Calibration gases consisting of mixtures of methane in nitrogen at concentrations of approximately $0.5,2.0,4.0$, and 5.0 percent are provided. The exact concentration is indicated on the individual cylinders.

A calibration curve is constructed by analyzing each standard using a gas chromatograph. The gas generating system is then adjusted to produce a variety of concentrations each of which is analyzed. Subsequent operations depend on whether the system will be set to produce a specific concentration or whether it will be used to produce random concentrations.

A typical calibration curve is shown in Figure 4. The system was attached directly to a gas chromatograph through the connection marked "sample out". Various concentrations of methane were generated by varying the flow of methane. The 
data from which the curve was constructed is given in Table 1. The calibration curves for FM-1 and FM-2 are shown in Figures 5 and 6 . The chromatograph was calibrated with various known concentrations of methane in nitrogen as discussed later. It is obvious that above 2 percent methane the predicted concentration is higher than that observed. This type of calibration is adequate for use when random concentrations are generated and when it is not necessary to set the system at a specific concentration. If a specific concentration or a series of specific concentrations are needed then a somewhat more complicated calibration procedure is followed. This involves setting a constant flow of methane and changing the air flow at which specific concentrations of methane will be produced. A single setting of methane flow, if of the proper magnitude, can be used to produce concentrations of methane from 0.5 to greater than 5.0 percent. The generator is adjusted for a methane flow of about $0.041 / \mathrm{min}$. and a series of mixtures are prepared at measured air flow rates. The signal is measured for each concentration produced and the actual concentration of methane is calculated. A curve can then be constructed of air flow versus methane concentration. The curve, however, is not linear and a more convenient form in which to represent the data is to plot the methane concentration against the reciprocal of the air flow. It is then quite easy to determine the air flow necessary to produce any concentration of methane at the fixed flow of methane.

Table 2 presents data obtained at a methane flow of 0.0412 $1 / \mathrm{min}$. and at varying flows of air. The concentration is that calculated from the observed signal and calibration data obtained with standards of known methane content. Figure 7 is a plot of methane concentration versus the reciprocal of the air flow. Table 3 is constructed from Figure 7 and is simply the air flow required to produce specific concentration of methane at the indicated flow of methane. The flow of methane is in all cases considerably less than that of air and control of the methane flow, or more precisely the adjustment of methane flow to a particular value, is much more difficult than the adjustment of air flow to a particular value. This is the only reason for using a fixed flow of methane and varying the flow of air to produce varying concentrations of methane.

Table 4 represents the reproducibility possible when the system is operated to produce specific concentrations of methane. The three sets of values, I, II and III, were obtained on three different days by the procedure just described. The relative standard deviation does not exceed 5 percent in the worst case and the reproducibility is certainly adequate for the calibration of methanometers. 
The accuracy with which a mixture of methane can be prepared depends on how carefully the system is calibrated. The standards provided with the system are compounded by a pressure technique with an inaccuracy of about 1 percent. If the system is carefully calibrated using these standards it should be possible to produce mixtures known with the same degree of accuracy. However, such accuracy will seldom be required for the calibration of conventional methanometers or similar devices. The system is operated with the least degree of accuracy when mixtures are prepared using the measured flow rates of the methane and air to calculate the methane concentration. The maximum error using this method of operation is about \pm 10 percent at concentrations of 5 percent methane. The error becomes smaller at lower concentrations and at 2 percent methane it is about \pm 3 percent. The error at higher concentrations is due to a system phenomenon while the error at the lower level is random and is almost entirely due to imprecise reading of the flowmeters.

\section{CHROMATOGRAPHIC ANALYSIS OF METHANE MIXTURES}

The gas mixtures produced by this system can be treated as binary gas mixtures providing that the chromatographic detector is sensitive only to one constituent, methane not air. A flame ionization detector is ideally suited for this analysis because of the low sensitivity to oxygen and nitrogen. The sensitivity of this detector is so low for air that at the concentrations of methane measured the contribution of air is not measurable. Therefore, it is not necessary to use a column that will separate methane from air but it is only necessary to use a column which will retain methane slightly and which will yield a peak which can be easily measured. In the studies described here peak areas were measured electrically and the conditions were adjusted so that the methane peak appeared in less than one minute. The operating parameters are given below and a schematic diagram of the sampling system is shown in Figure 8 .

Column packing

Column length and diameter

Column temperature

Carrier flow rate

Sample volume
50 percent vinyl substituted silicone rubber

$6^{\prime} \times 1 / 8^{\prime \prime}$

$25^{\circ} \mathrm{C}$

$60 \mathrm{cc} / \mathrm{min}$.

$2 \mathrm{cc}$ 
A sample is withdrawn from the manifold by applying a slight vacuum at the outlet of the gas sampling valve. Sample flow through the valve was adjusted to an approximate flow of 100 cubic centimeters per minute (cc/min.). Just before injecting the sample into the chromatograph, the vacuum control valve was closed and as soon as the flow shown by the sample flow meter had dropped to zero, the sample was injected. This assured that the pressure in the gas sampling loop was the same from sample to sample.

\section{RESPONSE TIME - GENERATING SYSTEM}

The generation system reaches equilibrium in a very short time after a change in flow of either methane or air. The time required is somewhat less than 2 minutes depending on the total rate of flow. Figure 9 is a graphical representation of the time required to reach equilibrium after an adjustment of flow rates to produce a change in concentration. Prior to zero time the system was adjusted to produce 2 percent methane. The flow of air was changed and a sample was withdrawn from the manifold for analysis as soon as possible. This first analysis is shown as zero minutes. Samples were withdrawn periodically for analysis and the concentration was changed several times during these analyses. The data from which Figure 9 was drawn is shown in Table 5 .

\section{RESPONSE TIME - EXTERNAL EXPOSURE CHAMBER}

The response time of the system in terms of the time required to reach equilibrium in the manifold is quite short but the time required to reach equilibrium in the external exposure chamber is considerably longer. The sample is conducted directly from the manifold into the external chamber but the time required to flush the external chamber of the previous sample is about 12 minutes. Figure 10 is a graphical representation of the measured concentration of methane in the chamber as the chamber was flushed with air and with samples of different concentrations of methane. The chamber contained a mixture of methane in air at somewhat less than 2 percent. At time zero the first sample was analyzed after air only at a flow of $21 / \mathrm{min}$. had been flowing for about 1 minute. The concentration of methane was adjusted to 2.0 percent at 15 minutes, to 0.5 percent at 32 minutes and to 0 percent at 49 minutes. At 50 minutes, the flow of air was increased to 8 $1 / \mathrm{min}$. The data on which Figure 10 is based is shown in Table 6 . 
A. Procedure

1. Connect air and methane as described in Section 2.

2. Calibrate analytical system using gas standards consisting of methane-nitrogen mixtures.

3. Connect analytical system to connection marked "Sample out" at rear of chassis.

4. Adjust flow of methane and air to predetermined values.

5. Analyze methane concentration produced by system using the analytical system.

B. Calibration of Methanometers pumps .

1. Methanometers equipped with sample probes and internal

a. Insert probe into manifold. Cap the connection marked "Sample Out" before activating methanometer.

b. Begin sampling.

c. Change methane concentration as described previously.

2. Methanometers without pumps and which depend on diffusion. Out".

a. Remove cap or plug from connection marked "Sample

b. Connect external exposure chamber to connection marked "Sample Out: with 1/4" copper tubing.

c. Place methanometer in chamber with methanometer in operating mode.

d. Adjust flow rate of air and methane.

e. Cap front connection on manifold with pipe cap provided or with cork of proper size.

f. Adjust methane and air flow to produce concentrations needed for calibration, allowing at least 12 minutes to reach equilibrium. 
The system is adequately protected from internal ignition but at times mixtures of methane in air at or above the explosive limit may be present in and around the manifold and in the external exposure chamber. The flow through the system is very low when high concentrations are being generated and the concentration external to the system will quickly drop to safe levels. The quantity of methane released by the system is always small and in most operational modes would not exceed about $0.04 \mathrm{l} / \mathrm{min}$. This quantity of methane poses no threat to safety. However, the volume of the external exposure chamber is sufficient to pose a slight threat if an ignition occurs when an explosive mixture is present. Consequently, the exposure chamber should be positioned so that the removable side is positioned away from the operator. The removable side is lightly held in place with springs which should allow almost instant release if an ignition occurs. In any case, the danger is slight and can be eliminated entirely by restricting the production of mixtures to those below the explosive limit. A little common sense and care will prevent even minor difficulties.

\section{PARTS AND MAINTENANCE}

Table 7 shows the commercially available parts that were used in the construction of this system. These parts were chosen because of their availability and parts from other manufacturers of similar operating characteristics may be substituted. The only other parts of the system which are not readily available and which were constructed specifically for this apparatus are the mixing chamber, the manifold, and the external exposure chamber. The exposure chamber is constructed from 1/4" clear plastic with the approximate dimensions shown in Figure 12. The joints may either be glued or fastened with machine screws.

The manifold, Figure 11 , is constructed from two reducing tees, a short length of $13 / 8$ " copper pipe, two reducing bushings, three brass tube connections, and a $1 / 2 "$ pipe to tube adapter. The dimensions are not critical but the overall internal dimensions of the manifold should be about 8 " long by $11 / 4$ " in diameter. The tube fittings are machined or bushed to fit a $1 / 2 "$ i.d. opening while the copper pipe to tube adaptor is chosen to fit. Connections are either soldered or brazed. The interior should be thoroughly cleansed of flux after fabrication.

The mixing chamber is made from a single reducing tee, two reducing couplings, and three $1 / 4$ " tube fittings. The mixing 
chamber is soft soldered or brazed. The reducing bushings used for both the mixing chamber and the manifold are one size smaller than the reducing tees and fit within the tee.

The only parts of the system which may ever need maintenance are the flow controllers and the flow meters. The flow controllers are protected from particulate contamination by the filters which serve also as flashback arresters. If they become inoperative because of particles lodging in the orifices they may be removed and replaced or may be disassembled and cleaned. The flowmeters will not require maintenance unless they are grossly contaminated with grease or dirt. If this should occur they should be removed and cleaned by flushing with a solvent. They should be thoroughly dried after cleaning to prevent contamination of the system with hydrocarbons other than methane.

Certain commercial equipment, or materials are identified in this paper in order to adequately specify the construction. In no case does such identification imply recommendation or endorsement by the National Bureau of Standards, nor does it imply that the material or equipment identified is necessarily the best available for the purpose. 


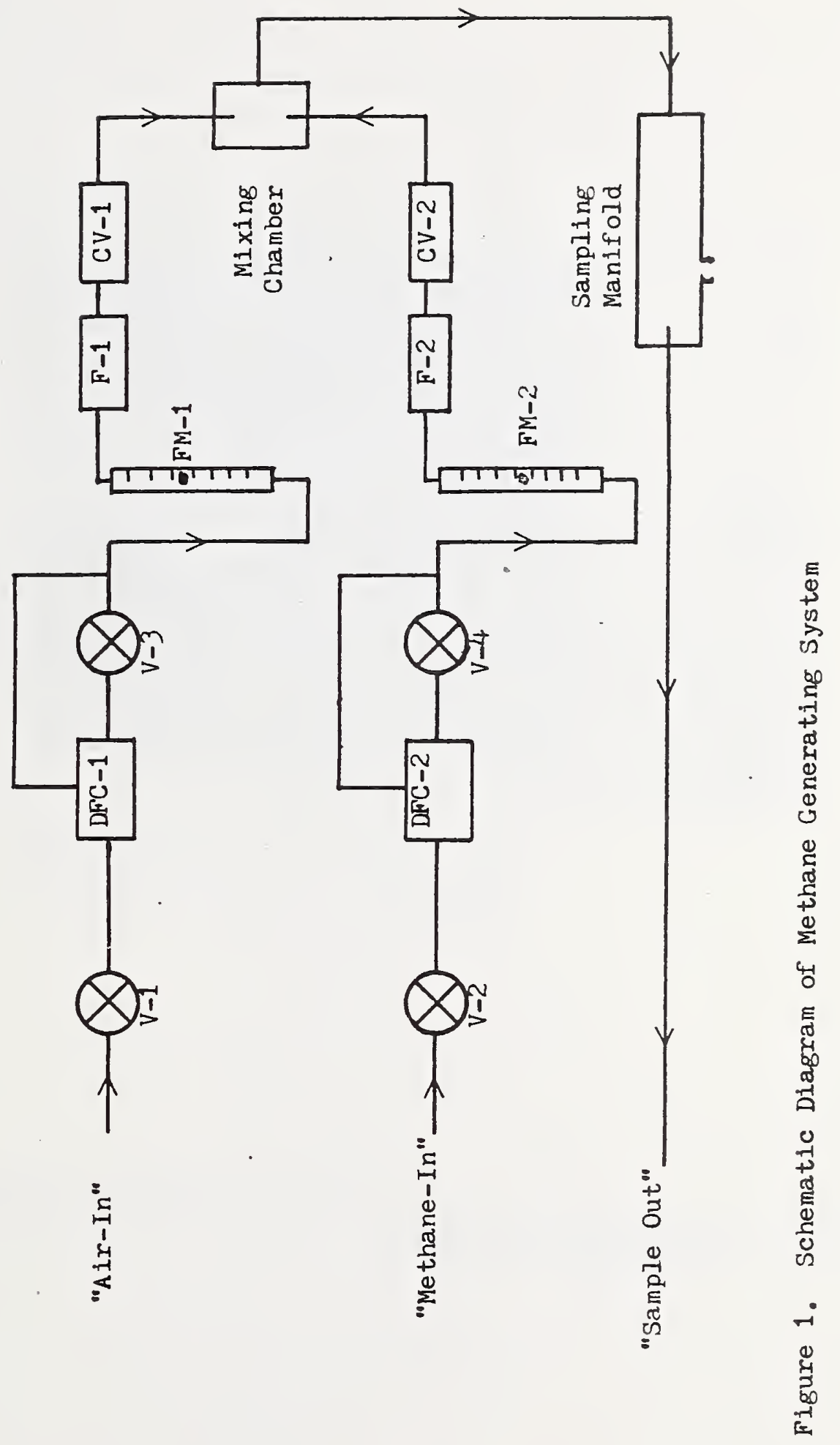




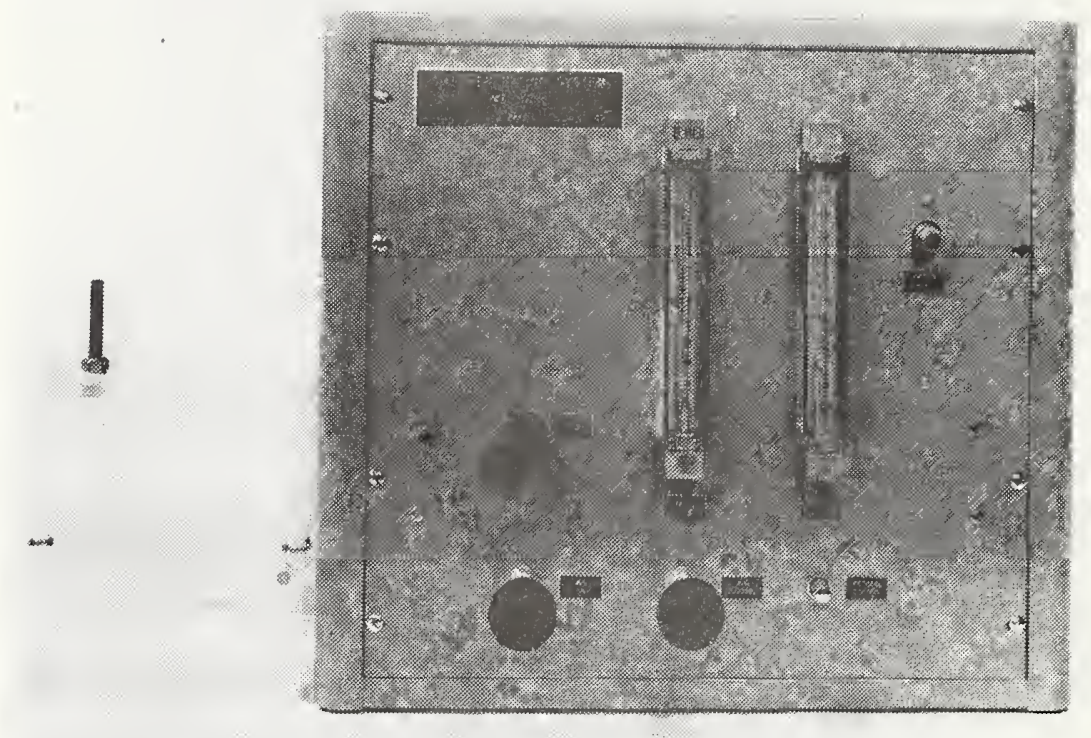

Figure 2. Photograph of the Front of Methane System Including Separate Chamber. 


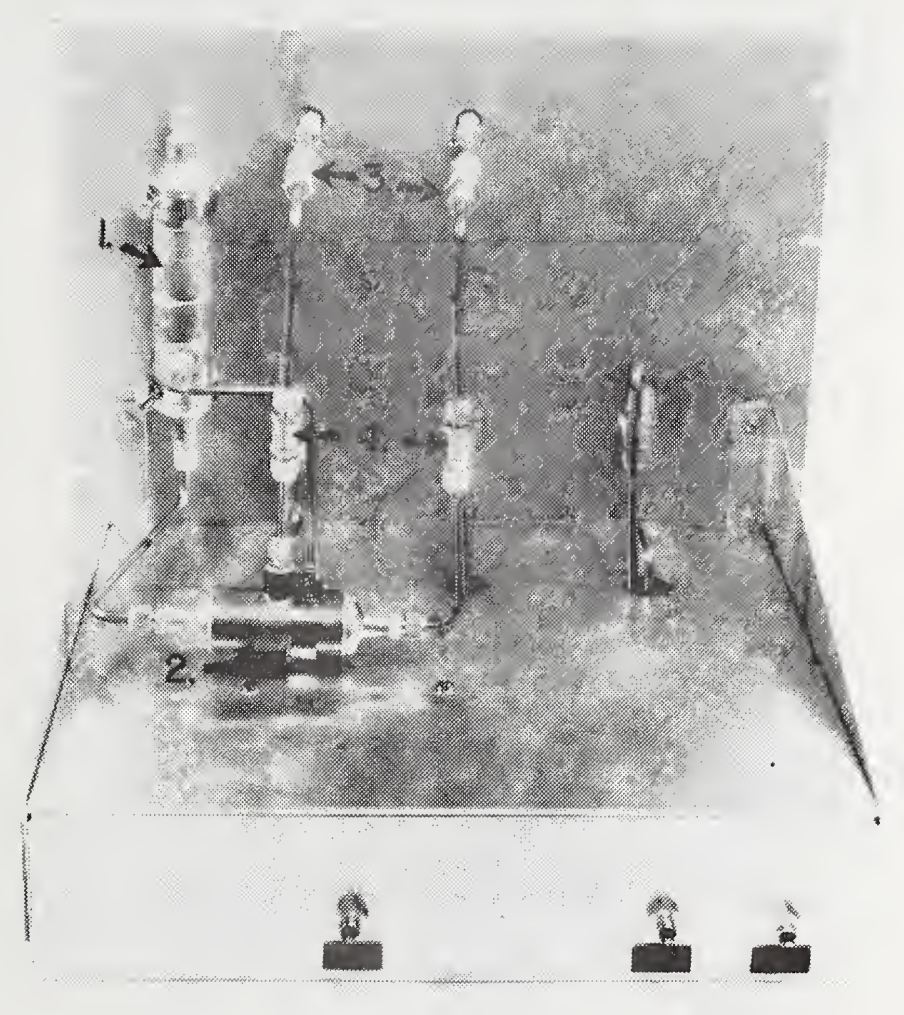

Figure 3. Photograph of the Rear and Interior of Methane System 


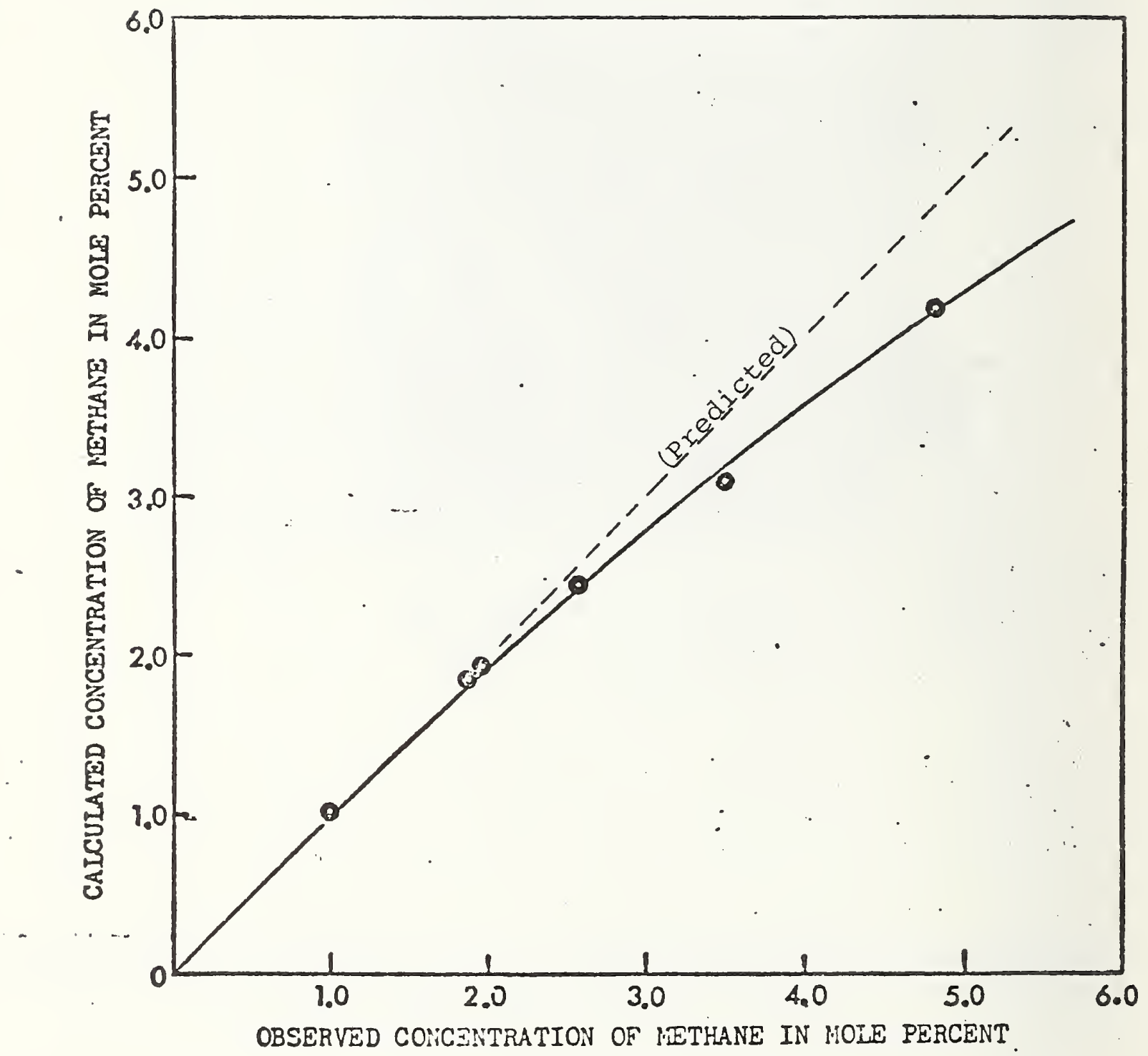

Figure 4. Typical Calibration Curve. 


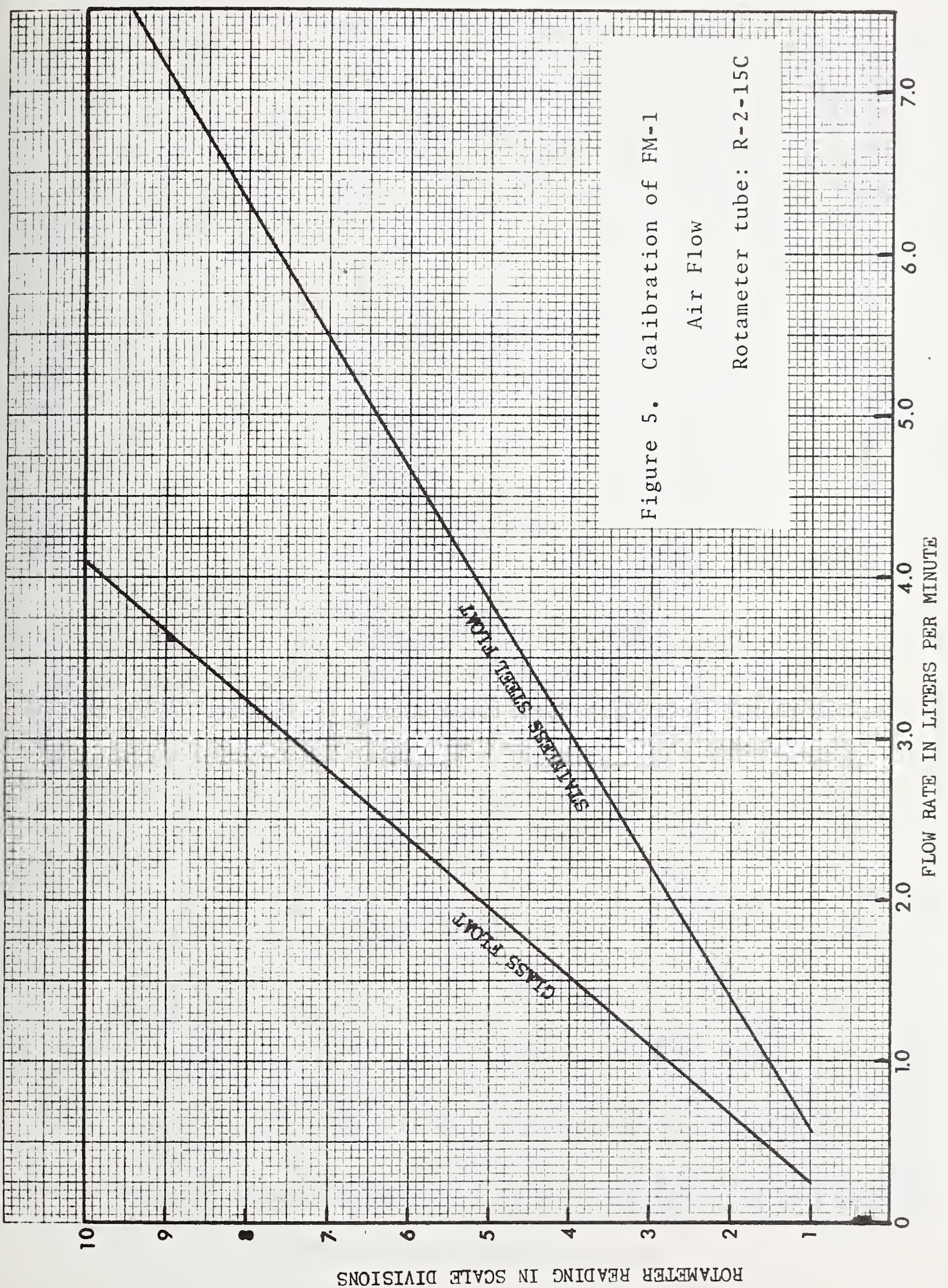




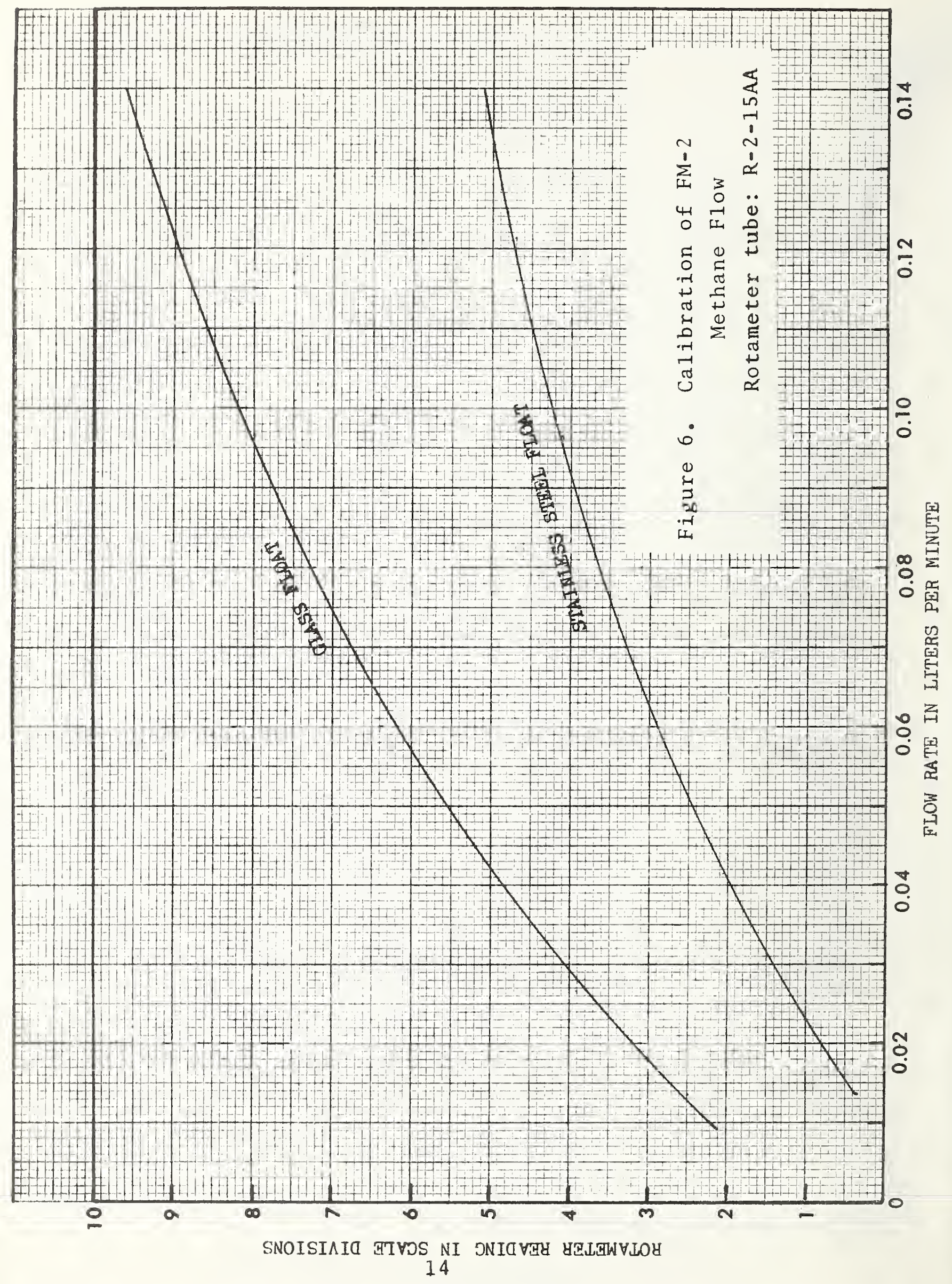




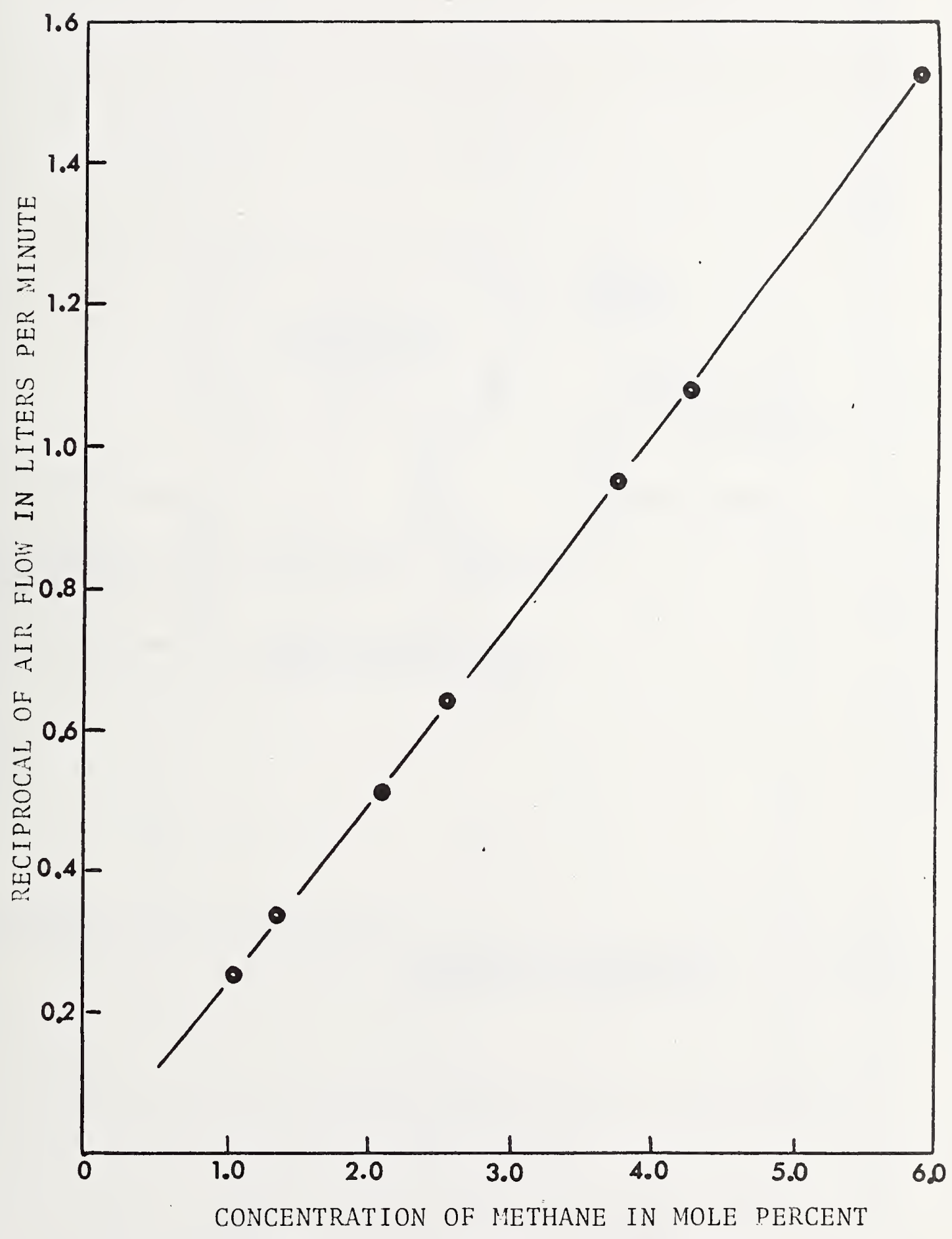

ligure?. Plot of Reciprocal of Air Flow Versus Concentration of Methane Produced at a Fixed Flow of Methane. 


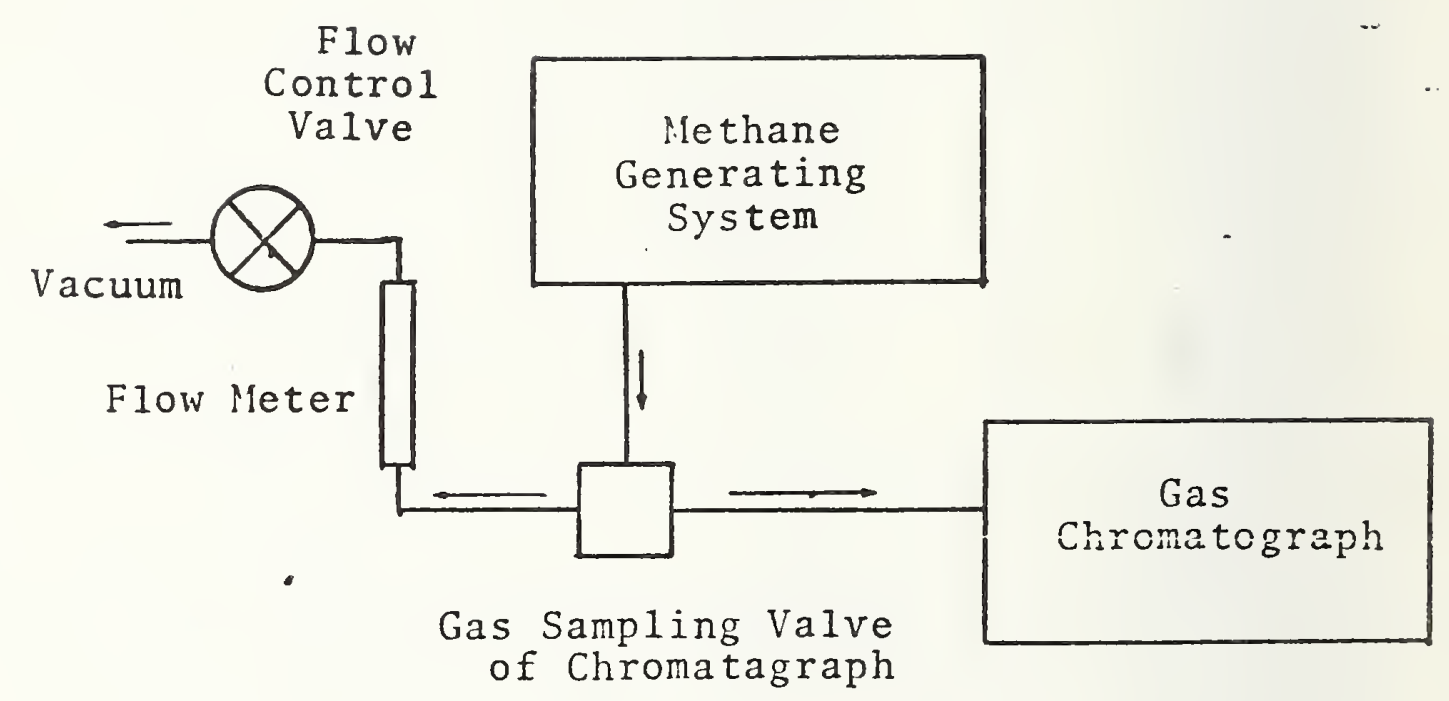

Figure 8. Schematic Diagram of Gas Chromatograph Sampling and Analysis System. 


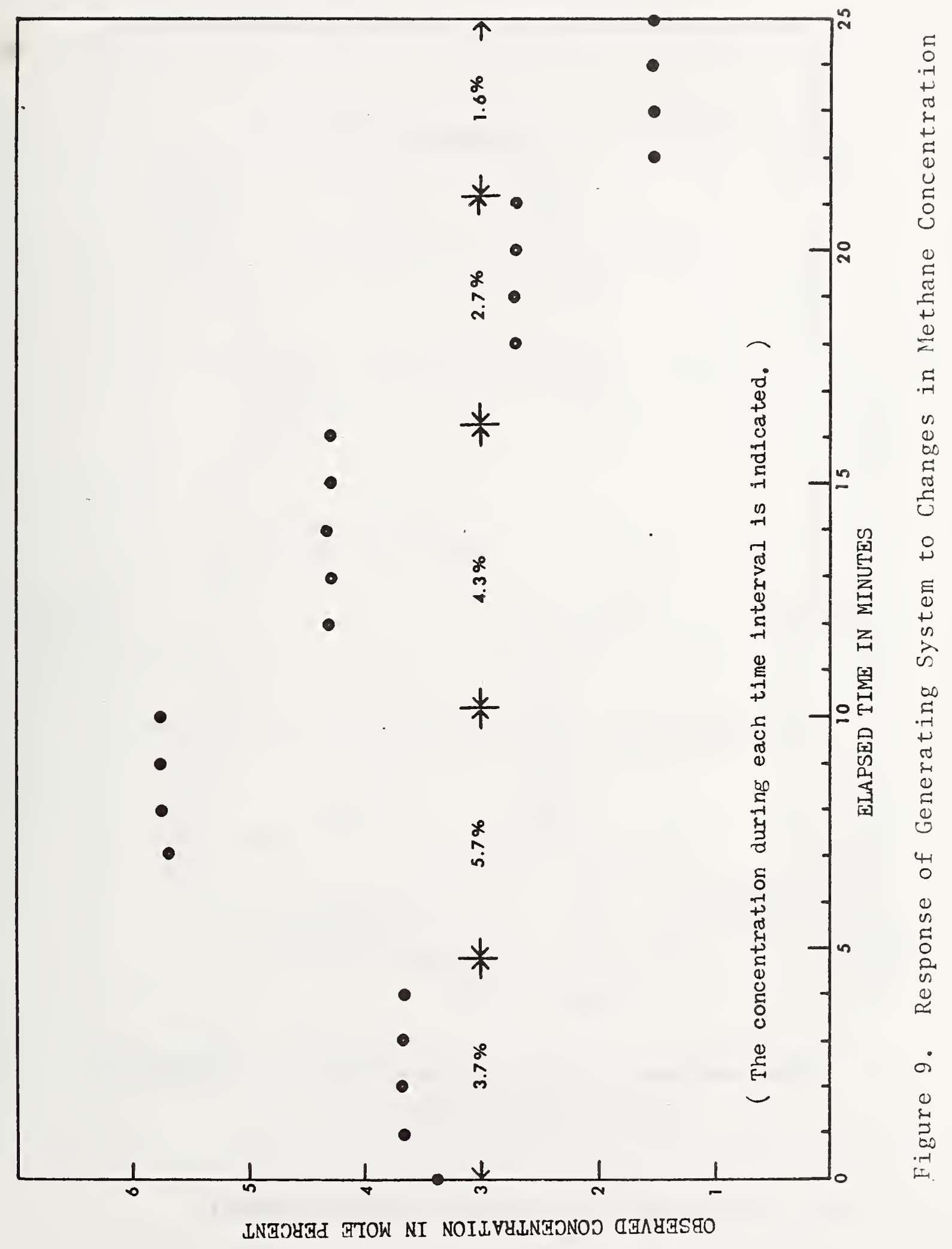




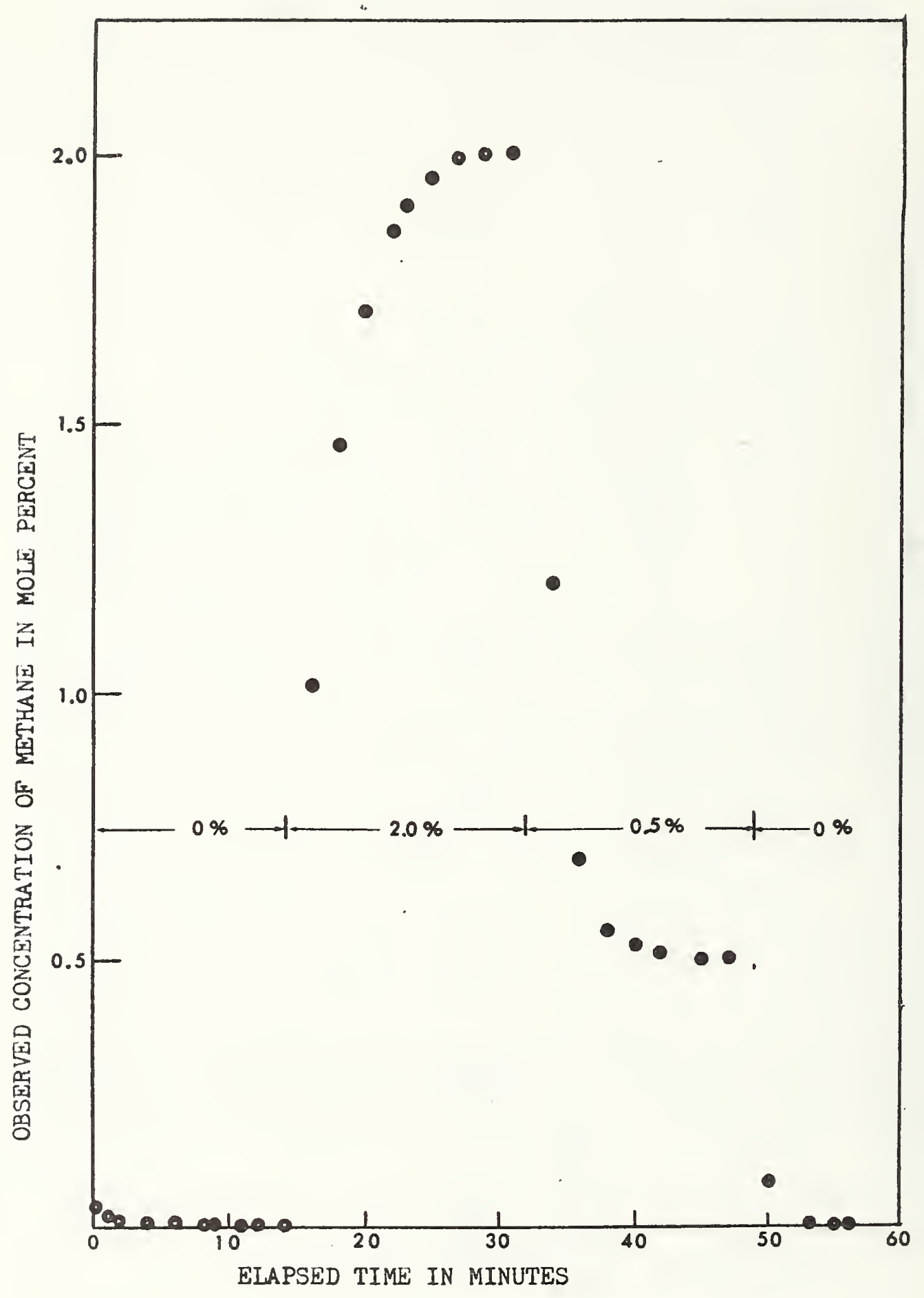

Figure 10. Response Time of External Exposure Chamber. 


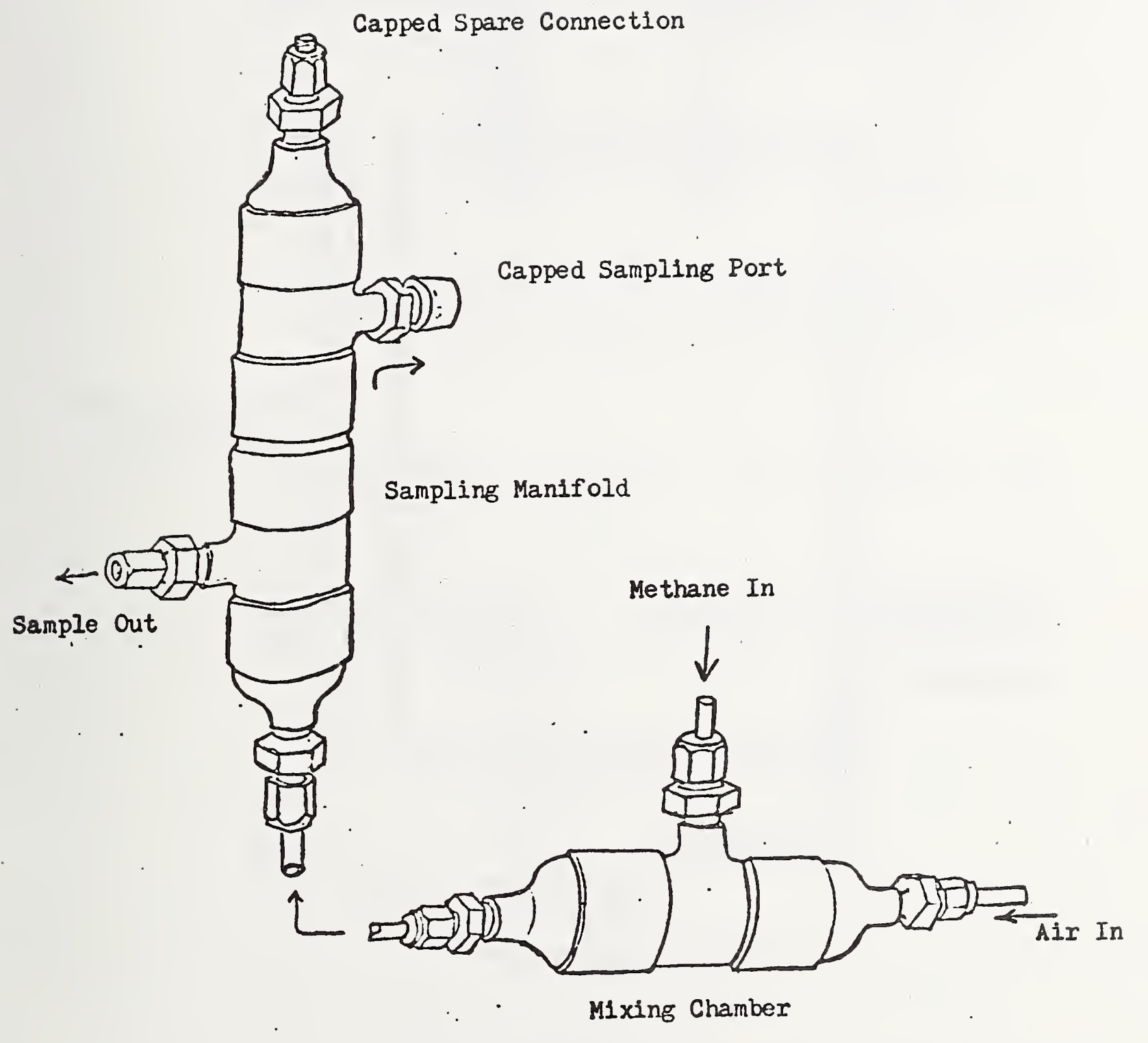

Figure 11. Sketch of Mixing Chamber and Sampling Manifold 


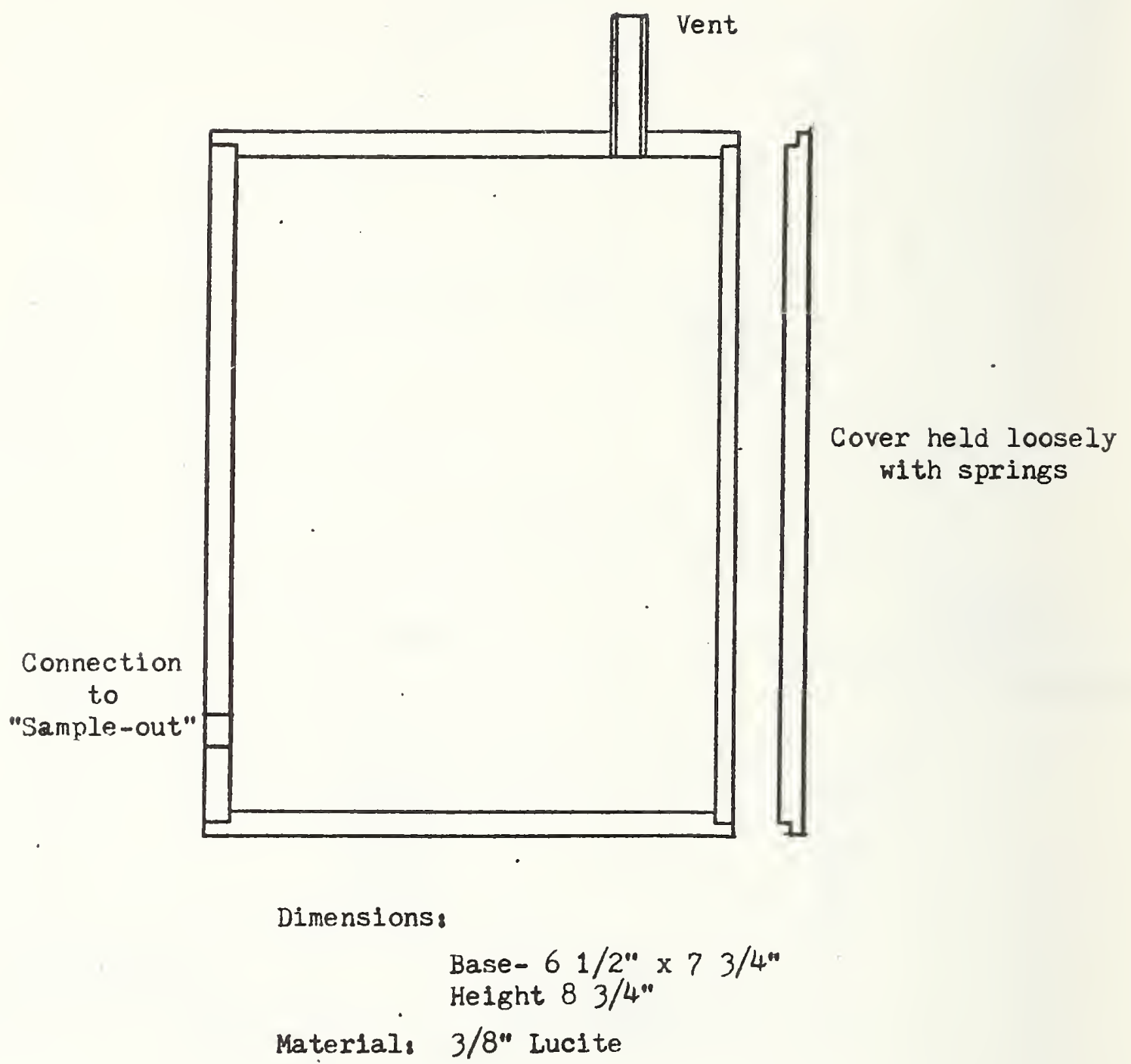

Figure 12. Sketch of External Exposure Chamber 
Tab1e 1. Typical Calibration Data

Flow Rate

Liters per Minute

Air

1.98

1.98

1.98

1.98

1.98

1.98

\section{Methane}

0.099

.0370

.0375

.0200

.0525

.0715
Concentration of Methane

$\frac{\text { in Mole Percent }}{\underline{\text { Calculated* }}}$

4.76

1.83

1.86

1.00

2.58

3.53
4.20

1.83

1.86

1.06

2.48

3.09

* Based on observed flow rates of air and methane.

* Based on calibration of chromatograph with 5.0 mole percent methane in nitrogen standard.

Table 2. Data Obtained at Constant Flow of Methane and Various Flows of Air

Observed Flow Rate Liters per Minute Air Methane

0.93

0.66

3.02

4.03

1.95

1.56

1.05
0.0412

.0412

.0412

.0412

.0412

.0412

.0412
Observed Concentration of

Methane in Mole Percent
3.80

4.95

1.35

1.01

2.01

2.43

3.43 
Table 3. Air Flow Necessary to Produce Specific

Concentrations of Methane at Fixed Methane Flow

Methane Concentration in Mole Percent

0.5

1.0

1.5

2.0

2.5

3.0

3.5

4.0

4.5

5.0
Flow of Air in Liters per Minute*
7.7
4.6
2.7
2.0
1.6
1.3
1.1
1.0
0.88
.78

* Methane flow fixed at 0.0412 1iters per minute.

Table 4. Reproducibility of the System When Used to Produce Specific Concentrations of Methane

Methane Concentration Mole Percent
Required Air Flow $\frac{\text { Liters per Minute }}{\text { I }}$

7.40

4.08

2.77

2.06

1.63

1.33

1.11

0.93

.79

.71
7.40

4.16

2.77

2.06

1.61

1.32

1.11

0.95

.83

.74
7.70

4.00

2.63

1.91

1.53

1.25

1.06

0.91

.79

.70
Average Relative s.d.

7.53

2.0

2. 0

2.9

2.72

2.01

1.59

1.30

1.09

0.90

.80

.72
4.5

3.1

3.1

2. 8

2.2

2. 5

2.8 
Table 5. Response Time of Generating System

Time in Minutes

$$
0
$$

1

2

3

4

5

7

8

9

10

11

12

13

14

15

16

17

18

19

20

21

22

23

24

25
Concentration of Methane

$$
\text { Calculated from Flow Rates }
$$
at Indicated Time
Observed

Concentration

$$
3.68
$$$$
5.74
$$

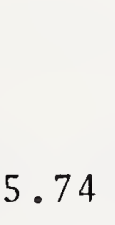

4.33

3.34

3.67

3.69

3.69

3.68

5.70

5.73

5.75

5.74

4.35

4.33

4.33

4.32

4.33

2.73

2.73

2.74

2.72

2.74

1.56
1.58

1.57

1. 56 
Table 6. Response Time of External Chamber

Time of Analysis

in Minutes

0

1

2

4

6

8

9

11

12

14

15

16

18

20

22

23

25

27

29

31

33

34

36

38

40

42

45

47

48

50

51

53

55

56
Observed Concentration of Methane in Percent

0.03

.02

.01

.008

.005

.003

.002

.002

.001

.001

1.01

1.46

1.72

1.86

1.92

1.96

2. 0

2.0

2.0

Concentration adjusted to $0.5 \%$

1.2

0.69

.56

.53

.51

.51

.51

Concentration adjusted to $0 \%$

0.09

.009

.003

.002 


\section{Table 7. Parts List}

Part Designation (Fig. 1)
Manufacturers Part or Description Catalog Number
On-off valve, Whitey On-off valve, Whitey Metering Valve, Whitey Micro-metering Valve, Nupro

FM - 1

FM- 2

DFC -1

DFC -2

Flashback Arresters

Check Valve
Flowmeter, Brooks

Flowmeter, Brooks

Diff. Flow Control, Moore 63BD Diff. Flow Control, Moore 63BDL
4VS 4

IVS4

4 RS 4

Nupro 4F-60

Nupro $\quad 4 \mathrm{C}$ 



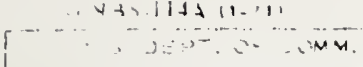

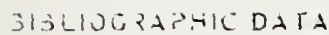 S, S E E T

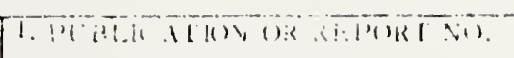
NBSIR 73-255

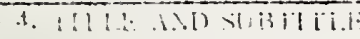

System for proparation of Known Concentrations of Yethine in Air

National Institute for Occupational Safety and Health

Cincinnati, Ohio 45202

13. Type of Report \& Periud Cuvered

\section{Final}

14. Sponsoring A gency Cole

15. SUPPLEMENTARY NOTES

16. ABSTRACT (A 200-word or less factual summary of most signific ant information. If document includes a significant bibliography or literature survey, mention it here.)

A gas generating system is described for producing concentrations of methane between 0.5 and 5.0 mole percent in air or other gases. The system has been evaluated and calibration procedure is described. The system is equipped with adequate safety measures so that mixtures in the explosive range can be generated safely.

77. KEY WORDS (Alphabecical order, separared by semicolons) Explosive mixtures; Gas mixes; Industrial hygiene; Methane; Mine safety.

13. AVAILABILITY STATEVENT

UNLINITED.

XXFOR OFFICI AL DISTRIBLTION. DO NOT RELEASE TO NT!S.

\begin{tabular}{|c|c|}
\hline $\begin{array}{l}\text { 19. SECURITY CLASS } \\
\text { (THIS REPORT) } \\
\text { UVCL ASSIFIEI) }\end{array}$ & $\begin{array}{l}\text { 21. NO. OF PAGES } \\
31\end{array}$ \\
\hline $\begin{array}{l}\text { 20. SECLFITY CLASS } \\
\text { (THIS PAGE) } \\
\text { UNCLASSFIED }\end{array}$ & 22. Price \\
\hline
\end{tabular}




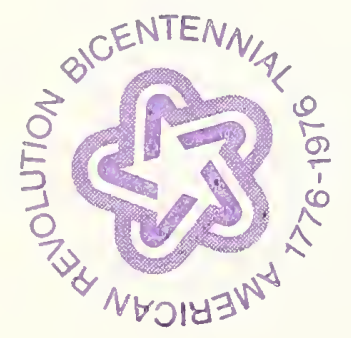

